\title{
Building comparable synthetic health-related indicators of air quality in cities
}

\author{
C. Aschan-Leygonie ${ }^{1} \&$ S. Baudet-Michel ${ }^{2}$ \\ ${ }^{1}$ Université de Lyon, UMR Environnement, Ville, Société, France \\ ${ }^{2}$ Université Paris-Diderot, UMR Géographie-cités, France
}

\begin{abstract}
Working on the relationship between respiratory health and atmospheric pollution in French cities led us to adopt a perspective that considers the risk for a single city of showing high levels of respiratory health problems. The risk level in a city is dependent on population vulnerability, the city context and pollutant levels. This presentation focuses on the observation of the unequal pollution hazards in French cities on a macro-scale. The study field covers 34 French cities of more than 100,000 inhabitants. The aim is to build different synthetic indicators of atmospheric pollution that consider the temporal and spatial diversity within a city, and to compare the different results. The focus is on the results for nitrogen dioxide $\left(\mathrm{NO}_{2}\right)$ over the 2007 and 2008 winter season. The paper presents the database and methodology used. The findings show that the spatial structure of air pollution between the cities remains globally the same whatever the indicator chosen. However, the results also show significant changes in the relative position of certain cities. When comparing the more conventional indicator calculated from mean daily concentrations in urban monitoring sites with an indicator also taking into account the concentrations observed in roadside stations, relative changes appear for more than ten cities. These findings highlight the importance of the criteria used in the choice of the indicators, and the benefit of using a set of complementary indicators in epidemiological studies.
\end{abstract}

Keywords: air pollution, spatial variation, indicator, cities, environmental epidemiology. 


\section{Introduction}

This paper is part of a research program that aims at investigating the relationships between respiratory health and urban environment, at both local and regional level, for a large set of 56 French urban areas, from 100,000 inhabitants to 10 million. Following the recommendations of Huang and Batterman [1], who highlight the fact that exposure assessment practices in epidemiological studies are highly dependent on the geographical exposure indicators, the aim is to compare different indicators. The comparison is based on the results obtained from different synthetic indicators regarding their levels of air pollution. Two questions are addressed: How can one build comparable pollution indicators, at the global level of a city, that take into account the strong spatial variety in the pollution level within a city? How can one build comparable pollution indicators that take into consideration the daily pollution cycle with alternating peaks and lows? The paper focuses on cities of more than 100,000 inhabitants, defined as built-up areas, over the 2008 winter season (December 2007 to February 2008), as this is a high season for respiratory disease with no confounder such as pollens. The methodology is applied to nitrogen dioxide $\left(\mathrm{NO}_{2}\right)$ as this is reported to be one of the pollutants most closely related to respiratory disease and is the best-surveyed pollutant within urban areas in France.

There are two main types of epidemiological study that consider the link between air pollution and health in urban environments. The first type is based on an exploration of the relationship over a time period at city level, and although the study often includes different cities, the aim is not to compare the urban situations. In the early 1990s, the APHEIS studies in Europe [2, 3] and PSAS [4] studies in France focused on the short-term relationship between morbidity and mortality levels for cardiovascular and respiratory diseases and levels of pollutants such as sulphur dioxide, nitrogen dioxide, ozone and particles of more than 10 or 2.5 microns. The relationship between the pollutant timeseries and health time-series was calculated using Poisson regressions. The health risk was calculated in each city usually for a particle size elevation of $10 \mu \mathrm{g} / \mathrm{m}^{3}$ : those risk levels rarely exceeded $1.5 \%$ [4].

The second type, which has been developed more recently [5], investigates health inequalities within cities and their link to air pollution. The local air pollution is estimated with a dispersion model with input data such as emission inventories, meteorological data, and concentrations of background pollution, and sometimes pollution registered by proximity monitors.

The present research aims to assess a city's global level of pollution, in order to compare it with other comparable French cities.

\section{Using the BDQA database to build comparable urban pollution indicators}

In France, air pollution monitoring has been obligatory since 1998 for cities with more than 100,000 inhabitants. ADEME (Agence De l'Environnement et de la Maîtrise de l'Energie) collects the pollutant concentration levels measured 
through a national network of independent agencies, the AASQA (Associations Agréées de la Surveillance de la Qualité de l'Air). Hourly mean concentrations are gathered in the BDQA database (Base de Données sur la Qualité de l'Air) and made available by ADEME.

$\mathrm{NO}_{2}$ is the best-surveyed pollutant with 250 monitors spread out across the 56 cities in 2009 (fig. 1). The maximum numbers of stations are found in large cities such as Paris (37), Lyon (16), Douai-Lens, Marseille (11 each) and Lille (10). Minimum numbers ( 2 monitors per city) are found in smaller places such as Nantes, Amiens, Avignon and Valence.

Survey monitors are located in three main location types: background sites, proximity sites and specific sites. The background monitoring sites measure the level of pollution that cannot be avoided by the population 24 hours' a day. They are located away from specific and important sources of pollution (in school playgrounds, park areas, pedestrian sites, etc.). The proximity stations measure

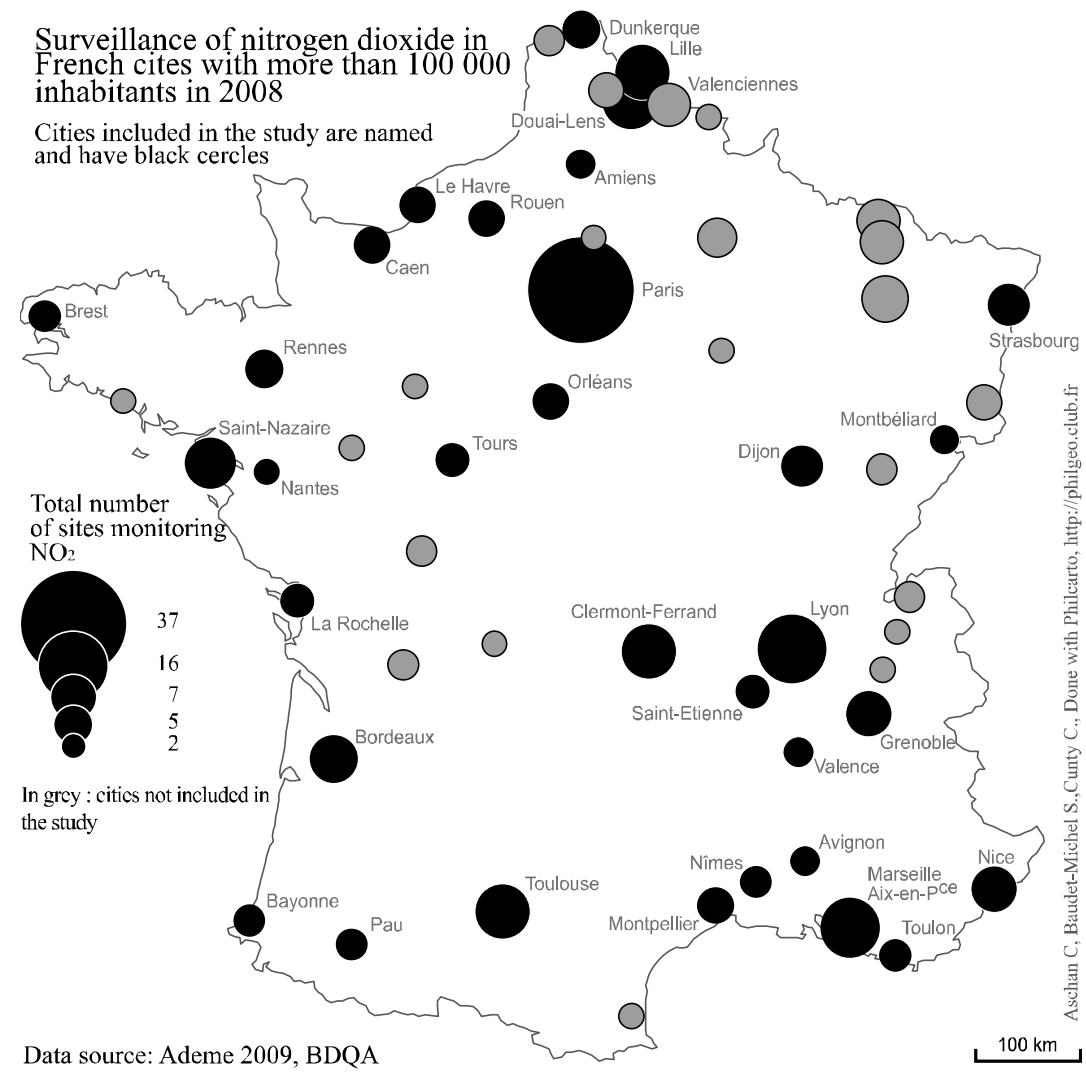

Figure 1: Surveillance of nitrogen dioxide in French cites with more than 100,000 inhabitants. 
pollution close to pollution sources, i.e. traffic if along a busy road, or industrial if next to an industrial plant. Specific stations will be located close to particular sources of pollution, such as airports, railway stations, incinerators. In 2009, French cities had 130 urban sites, 50 roadside sites, 50 suburban sites and 20 industrial locations monitoring nitrogen dioxide.

The indicators are built from concentrations of $\mathrm{NO}_{2}$ observed in two types of sites: urban background and roadside sites. As only 35 urban areas host roadside monitors, one urban area (Calais) lacks an urban background monitor and one city has too many missing values throughout the study period (Thionville), the sample for this study will be reduced to 34 cities (fig 1). Thus, the BDQA (Base de Données sur la Qualité de l'Air) database opens up the possibility of building comparable synthetic indicators on a large sample of cities that address the diversity of pollution situations.

\section{Estimating ambient air pollution: a method integrating spatiotemporal variation}

The construction of indicators allowing the comparison of $\mathrm{NO}_{2}$ levels between cities should integrate both the spatial and temporal variation in pollutant concentrations in order to better approximate global exposure to pollution.

\subsection{Dealing with daily cycles: making use of four parameters}

As shown for Lyon (fig. 2), all cities feature two peaks with high concentration of $\mathrm{NO}_{2}$ and two lows. The time of day at which the peaks and lows occur varies slightly between cities, but the cycle observed in Lyon (peaks around 7-10 am and 5-8 pm and lows around 2 to 5 am and 1 to $3 \mathrm{pm}$ ) is fairly characteristic of French urban areas [6]. Therefore, parameters such as mean and median are not

Daily variation of $\mathrm{NO}_{2}$ in Lyon

(hourly median during December 2007, January 2008 and February 2008)

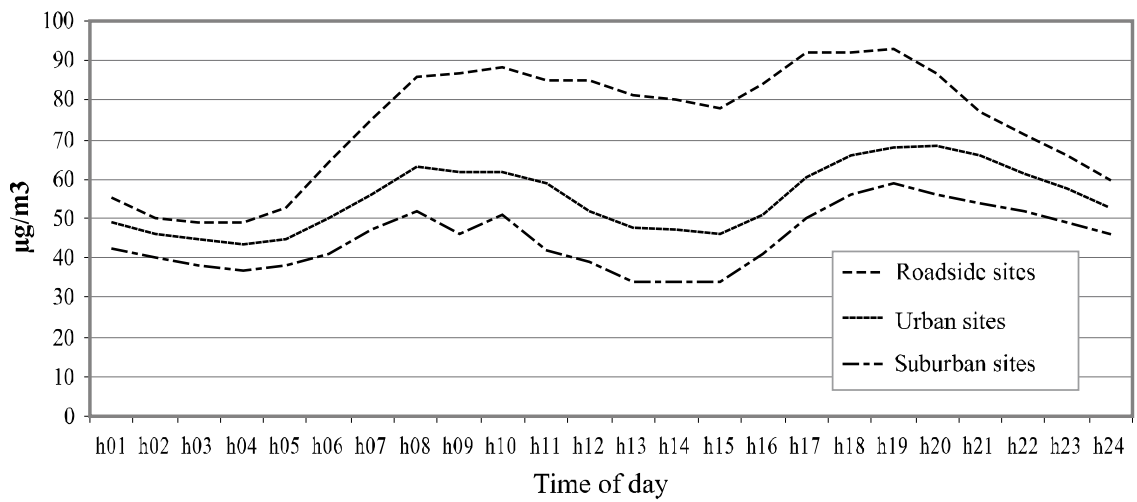

Figure 2: Daily variation of hourly median concentrations of $\mathrm{NO}_{2}$ (Lyon, winter season 2007-2008) (data source: BDQA). 
accurate synthesisers of daily pollution and other parameters have to be used. We believe comparison of air pollution in cities might be improved if observed according to a set of parameters. A set of four different parameters were created in order to estimate the global $\mathrm{NO}_{2}$ concentration level for each city: high and low percentiles and daily peaks and lows. Firstly, daily average values for each city were calculated from peak hours alone over winter 2008 for urban and roadside sites (peak average). Secondly, another set of daily mean values, this time from the lowest concentrations, was calculated for each of the 91 days of the study period, for urban and roadside sites (low average). Thirdly, for each day of winter 2008 , the $90^{\text {th }}$ percentile of the hourly $\mathrm{NO}_{2}$ concentrations was determined. Finally, the $10^{\text {th }}$ percentile of the hourly average was determined per day over the three month period.

\subsection{Addressing the spatial variability of $\mathrm{NO}_{2}$ concentration}

As shown for Lyon, nitrogen dioxide levels do not only differ from one hour to the next, but also naturally between different monitor types (fig.2). The averages observed in urban background sites are much lower in general and present a more homogenous profile than the traffic-related sites. The two urban monitors (St Just and Gerland) located within Lyon city centre present a mean value of the peak hours during winter 2008 of around $65 \mu \mathrm{g} / \mathrm{m}^{3}$, whereas the roadside sites register much higher means over the period $\left(>80 \mu \mathrm{g} / \mathrm{m}^{3}\right)$. Moreover the roadside sites show greater differences between the sites as they are directly affected by the intensity of the passing traffic (Garibaldi and the site near the A7). Surprisingly, the variability within the traffic-related sites over this period is generally lower for the traffic sites (relative standard deviation) of around 0.4 in urban sites and between 0.2 and 0.3 in roadside sites, except for the Grand Clément and Eastern ring road where variations are high.

A hierarchical ascendant classification (HAC) was used to test the differences in $\mathrm{NO}_{2}$ levels between the two types of sites (urban background sites and roadside sites). The classification was carried out on the peak average (7-10 am and 5-8 pm) during winter 2008. The dendrogram using Ward's criterion (fig. 3) shows a dichotomy between the $\mathrm{NO}_{2}$ concentrations observed in background monitoring sites (Gerland and Saint Just) on the one hand and in traffic-related sites on the other hand. These findings and the fact that the spatial variability of $\mathrm{NO}_{2}$ may mainly be allocated to two categories of land use (main roads and densely built-up areas) suggest that it is relevant to estimate the global air pollution of a city including the two monitor types.

Our work is based on the hypothesis that measurements in one type of monitoring site are representative of all those locations with similar features: urban background monitors are representative of all areas with a population density above 3,000 inhabitants per square kilometre, more than 100 meters away from a road with 4,000 to 7,000 vehicles per day and at least 200 meters away from a road with more than 7,000 vehicles per day. In the same way, ambient air concentrations measured in a roadside site are considered representative of all zones near to a road with more than 4,000 vehicles per day. 
Site (ind. levels) Dendrogram

Berthelot (4.76)

Vaise (9.65)

Grand Clément (4.09)

Eastern Ringroad (20.85)

Gerland (0.99)

Saint Just (4.75)

Lyon A7 (14.91)

Garibaldi (-)

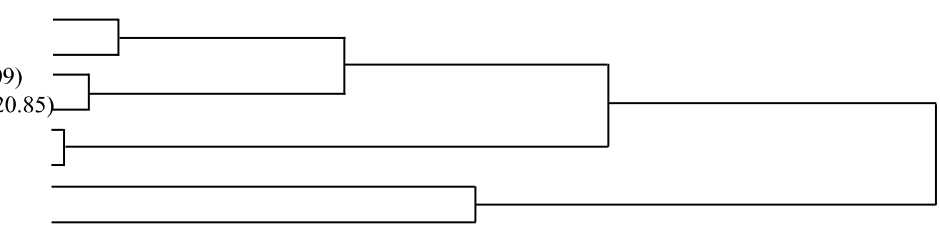

Figure 3: Ward's method based on $\mathrm{Chi}^{2}$ distances dendrogram based on the daily average concentrations of peak hours observed in background (in italic) and roadside sites (normal) in Lyon from December 2007 to February $2008(\mathrm{~N}=13)$ (ind. levels = intra class inertia).

Suburban background monitors and monitors located close to industrial plants have not been included in the study for two reasons: the location criteria are defined in such a way that these monitors survey specific pollutions (for example photochemical pollution in suburban sites) and few cities monitor $\mathrm{NO}_{2}$ in suburban or industrial areas.

In order to estimate the share of the two types of area within a city we used GIS. Two categories of land use defined by CORINE Land Cover (250 m gridbased database) were used to estimate the share, within the city limits, of continuous urban built-up areas (combined with a population density above 3,000 inhabitants per square kilometre) and road networks and associated land. A 50-meter buffer zone [7] from the roadside of the larger roads was applied, and for the urban canyon streets a smaller buffer zone was used (25 meters). Observed for Lyon, it resulted in a respective share of $70 \%$ for the continuous urban built-up areas and $30 \%$ of the roadside zones. In this first phase of the work, these ratios have been applied for all cities. Thus, to build up each global city indicator of $\mathrm{NO}_{2}$ concentration levels, the levels in both types of monitoring station were weighted; a coefficient of 0.7 was applied for urban monitors and 0.3 for roadside monitors.

\section{Results}

Six parameters using median values were calculated in order to compare the cities' relative positions with regard to $\mathrm{NO}_{2}$ concentrations. All were calculated for the 2008 winter. The parameters relying on low and peak hours and $10^{\text {th }}$ and $90^{\text {th }}$ percentile were calculated and used in order to produce a synthetic global indicator accounting for the daily variability in $\mathrm{NO}_{2}$ concentration, based on the use of traffic and urban monitors. Two classical synthetic parameters, similar to those used in epidemiological studies such as APHEIS, were calculated to be compared to the other four: one using daily means for urban monitors only, the other using daily means for traffic and urban monitors.

The first observation when comparing the parameters (table 1) is the obvious fact that the mean levels differ from one parameter to another. The introduction of traffic monitors into the calculations leads to an increase in all levels observed for the median of the daily means: the minimum rises from $15.7 \mathrm{ug} / \mathrm{m}^{3}$ to 
Table 1: $\quad$ Statistical parameters describing the different indicators for 34 cities.

\begin{tabular}{|c|c|c|c|c|c|}
\hline Type of monitoring sites & Variables & Mean & $\begin{array}{l}\text { Standard } \\
\text { deviation }\end{array}$ & Minimum & Maximum \\
\hline \multirow{5}{*}{$\begin{array}{l}\text { Urban background and } \\
\text { roadside sites }\end{array}$} & Low average & 29.3 & 8.4 & 17.0 & 51.0 \\
\hline & Peak average & 51.3 & 11.1 & 31.9 & 73.4 \\
\hline & $10^{\text {th }}$ percentile & 18.6 & 7.4 & 8.1 & 37.6 \\
\hline & $90^{\text {th }}$ percentile & 61.9 & 12.8 & 38.8 & 85.9 \\
\hline & Daily means (24 hours) & 39.3 & 9.6 & 23.0 & 63.5 \\
\hline Urban background sites only & Daily means (24 hours) & 33.6 & 8.9 & 15.7 & 55.2 \\
\hline
\end{tabular}

$23 \mathrm{ug} / \mathrm{m}^{3}$, the maximum from 55.2 to $63.5 \mathrm{ug} / \mathrm{m}^{3}$ and the mean from 33.6 to 39.3 $\mathrm{ug} / \mathrm{m}^{3}$. Other parameters calculated on traffic and urban monitors show the highest level of concentration for the $90^{\text {th }}$ percentile $\left(61.9 \mathrm{ug} / \mathrm{m}^{3}\right)$ and the peak hours $\left(51.3 \mathrm{ug} / \mathrm{m}^{3}\right)$ and the lowest level for the $10^{\text {th }}$ percentile $\left(18.6 \mathrm{ug} / \mathrm{m}^{3}\right)$ and the low hours $29 \mathrm{ug} / \mathrm{m}^{3}$. Very high linear correlations $(>0.84)$ are shown between all parameters (except with $\mathrm{P} 10 \mathrm{R}^{2}=0.7$ ), that means that all parameters rank the cities in quite similar ways.

In order to assess the pollutant levels within the cities a principal component analysis was conducted on the six parameters that render the daily variability of $\mathrm{NO}_{2}$ concentration levels. The PCA gives rise to a very strong first factor representing $92 \%$ of interurban variations in $\mathrm{NO}_{2}$ levels. This very high variance shows that the results obtained by the different indicators are very convergent. This result refutes our hypothesis that introducing spatial variability and not using mean values would radically change the results. It is the second axis that explains $8 \%$ of the inter-urban variations that shows in what way the choice of the indicators is important. This axis shows that the main difference is to be found between the indicators that are based on peak hours and those calculated from the daily lows. The factor scores oppose cities with high peaks and low levels of $\mathrm{NO}_{2}$ during the daily lows (at night and early afternoon) like Toulon, Nîmes and Clermont-Ferrand, to cities with low levels in peak hours and high concentrations during the daily lows (Strasbourg, Dijon, Le Havre, Rouen). The first component can be used to characterise the cities regarding their global pollutant level (fig. 4). Lyon, Valence, Paris, Marseille, Grenoble, Nice and Montpellier stand out as the most polluted cities (high scores for all indicators), opposite St-Nazaire, Brest, Rennes, Dunkerque, Orléans, Tours, Bayonne for the latter (low scores for all indicators). Around the gravity centre eleven cities with medium concentrations, like Bordeaux, Toulouse, La Rochelle. A regionalisation of the urban system appears that produces three classes of cities: the southeastern and eastern ones with Paris and Rouen, the north-western and western ones.

A comparison between the spatial organisation obtained from the parameters using only urban monitors and using both traffic and urban monitors (weighted according to land use) showed significant changes of ranking for two groups of 


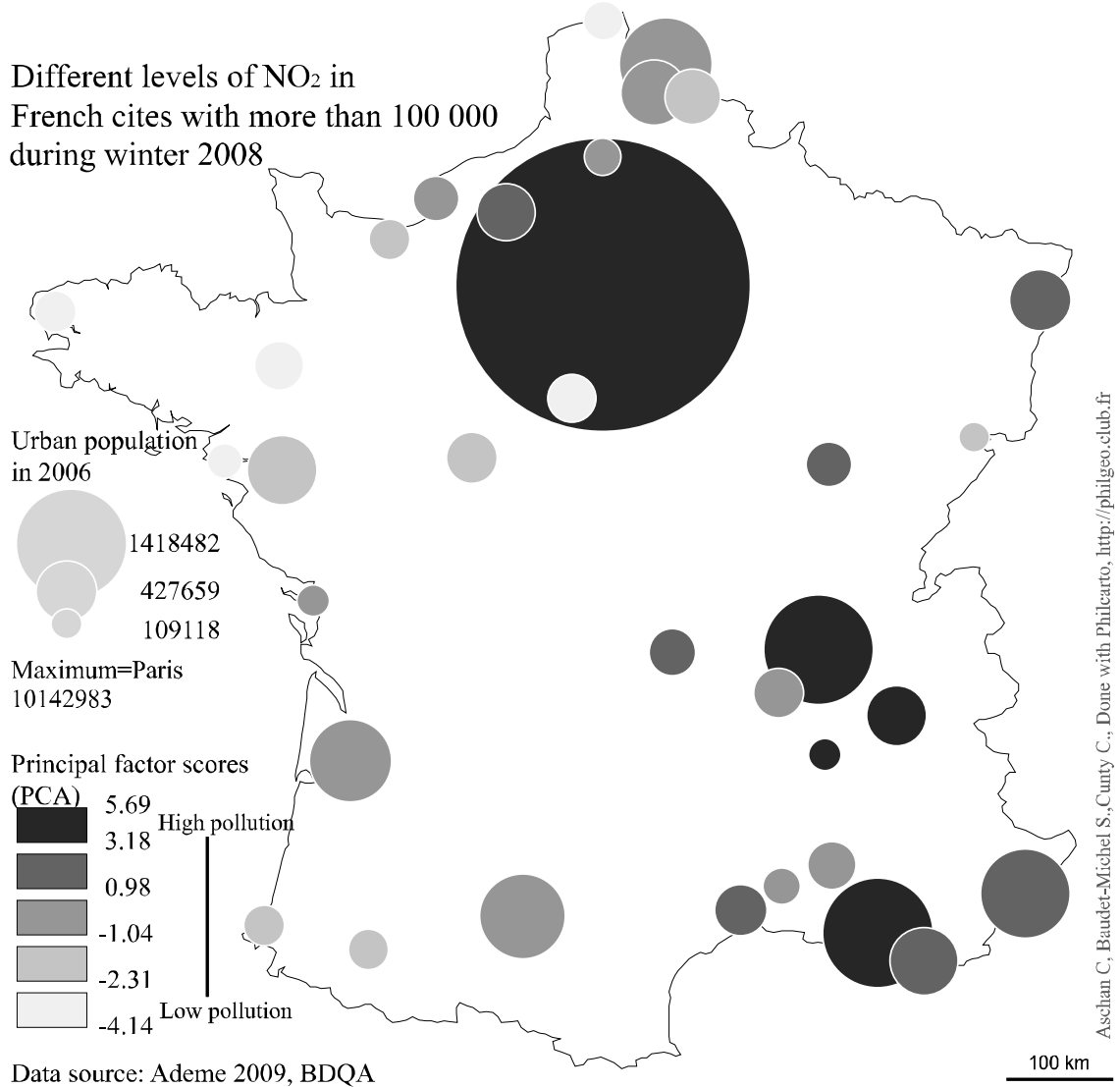

Figure 4: Cities position on the first axis of a PCA (six parameters describe nitrogen dioxide pollution level: peak and low hours, P10 and P90 and daily means from urban background stations only).

cities. The parameter used here to calculate the two synthetic indicators was in both cases the daily mean concentration, as is usual for epidemiological studies. The mean level for the sample of cities rises from 33.6 (urban monitors only) to $39.3 \mu \mathrm{g} / \mathrm{m}^{3}$ (urban and traffic). The minimum and maximum values show similar elevations. The comparison between these two indicators shows that cities such as Valence, Paris, Nîmes, Avignon, Rouen, Montpellier and Nice not only show higher $\mathrm{NO}_{2}$ concentrations, but their relative position in the sample of cities also changes, appearing more polluted in relation to the other cities than previously when using only urban monitors. Meanwhile Toulon, Amiens, Dunkerque, Dijon, Lille and Montbéliard appear to have $\mathrm{NO}_{2}$ concentrations that, although higher, rank them better in relation to the other cities. To us these results show that the use of urban, or urban and roadside monitors significantly changes the geography of polluted cities. It broadens differences between western (least polluted), south-eastern (most polluted) and south-western (averagely polluted) 
cities. Therefore, we believe that the traffic monitors should not be systematically put aside in epidemiological analysis.

\section{Discussion}

The global indicators proposed in this paper have been built using a set of monitors characterising different location types in order to respond to the fact that the use of one sole background monitor may not reflect the situation of large cities and may lead to accepting the zero hypothesis concerning the relationship between pollution level and morbidity.

The introduction of traffic monitors into the analysis, the use of most city monitors, responds to the remark made by Katsouyanni et al. [8] that a reliable representation of human exposure to atmospheric pollution would involve at least three monitors (regardless of the type of site). This allows a more accurate assessment of the diversity of inner city pollution. As shown in 3.2., traffic monitors and urban monitors capture different pollution situations that both reflect the diversity of urban spaces. As assumed by a number of authors [2-4], this paper demonstrate the roadside and urban monitor's global indicator shows a rise (compared to urban monitors alone) in the $\mathrm{NO}_{2}$ concentration level of all cities. However, this rise may be a better estimation of the global exposure situation of the city than the estimation from background monitors alone.

The interurban spatial structure remains globally the same whatever the indicator chosen. However, the results also show significant changes in the relative position of several cities. Comparing the more conventional indicator calculated from daily mean concentrations in urban monitoring sites with an indicator taking into account the concentrations registered by roadside monitors as well as urban ones introduces changes for almost a third of the cites. These findings highlight the importance of the criteria used in the choice of the indicators, and the benefit of using a set of complementary indicators, like the one proposed in the PCA. The use of daily means also appears to be less accurate than the use of for example percentiles.

Limits to our methodology are due to the comparative ambition that lead to the examination of a large set of cities and therefore do not allow the use of detailed information such as $\mathrm{NO}_{2}$ cadastre and mobile measurement series or results from dispersion models.

Firstly, the hypothesis that areas with similar location features have a similar level of $\mathrm{NO}_{2}$ pollution can be discussed. Even though the HAC showed a clear similarity between the pollutant levels observed in urban background locations on the one hand, and in traffic-related sites on the other hand, clearly there are numerous zones within a city for which the hypothesis of homogeneous pollution level derived from either traffic, either urban background sites is not defendable: as an example pollution level for traffic sites are different whether measured in large or small roads, in urban residential or urban working places... However, as it is impossible to make use of detailed information while looking at such a large set of cities, introducing variability relating to the identification of a monitor's location type seems to be a fair compromise. The weighting of $\mathrm{NO}_{2}$ 
concentrations according to the type of monitors could be improved and adjusted for each city using Corine Land Cover database.

Secondly, there are inequalities between cities regarding the quality of the surveillance of $\mathrm{NO}_{2}$ (and other pollutants), as 50\% host less than four monitor sites. Amongst the 56 largest cities in France, 19 do not survey traffic-related $\mathrm{NO}_{2}$. Although theoretically most monitor types should be found in every city, in reality, most cities only survey pollutants in two kinds of location. The AASQA have clearly favoured the background location, used in most health studies, while traffic monitors are too scarce. Even though pollution surveillance is now compulsory, the AASQA are responsible, in each city, for atmospheric pollution surveillance. The AASQA benefit from ADEME's guidelines and expertise in implementing their stationary network [9], but each ASQA decides for itself where to install permanent measurement stations, which pollutant to observe, when to expand their measurement network, and when to start observation of an emission campaign. They are independent agencies, but placed under the supervision of a management board where civil society, politicians and manufacturing companies operating in the city are represented. Therefore, strong interests are in conflict in AASQAs and the geography of each city's stationary network may result more in a compromise between political forces than in a scientific objectivity. Therefore, stationary networks can vary in density, seniority, variety of pollutant surveyed and monitoring sites. Thus, there are monitors that do not accurately reflect the air pollution of the type of area that they are supposed to represent.

\section{Conclusion}

The purpose of this work was to propose an alternative method for building indicators allowing registration of different urban exposure situations, which may be used in epidemiological and risk assessment studies. It shows that the BDQA, although not perfect, may be used in order to investigate spatial variations of global urban air pollution. Suggested improvements to the conventional use of mean concentrations, are based on the integration of spatial variability by weighting the measurements according to the share of different types of land use and to avoid smoothing the daily variations of $\mathrm{NO}_{2}$. Depending on the types of monitoring sites used in the indicator and the way of dealing with the daily variations in the pollutant concentration, the relative position of the cities with respect to the global pollutant level varies. These findings suggest that further investigations should be carried out on the relevance of certain indicators used in health studies.

\section{Acknowledgements}

This research has been supported by a contract from PIR Ville Environnement, an interdisciplinary research programme financed by CNRS (Centre National de la Recherche Scientifique) and the French ministry of Ecology and Sustainable Development (MEEDDM). 


\section{References}

[1] Huang, Y.L. \& Batterman S., Selection and Evaluation of Air Pollution Exposure Indicators Based on Geographic Areas. The Science of the Total Environment (253), pp. 127-144, 2000.

[2] APHEIS Health Impact Assessment of Air Pollution in 26 European Cities. Air Pollution and Health: A European Information System, Institut de veille sanitaire. Second year report, 232 p. 2000-2001.

[3] Wong, C. M., Atkinson, R.W., Anderson, H.R., Hedley, A.J., Ma, S., Chau, P.Y.K., \& Lam, T.H., A Tale of Two Cities: Effects of Air Pollution on Hospital Admissions in Hong Kong and London Compared. Environmental Health Perspectives 110(1), pp. 67-77, 2002.

[4] Lefranc, A., Blanchard, M., Borelli, D., Chardon, B., Declercq, C., Fabre, P., Jusot, J.F., Larrieu, S., Le Tertre, A., Pascal, L., Prouvost, H., Rivière, S., Wagner, V., Cassadou, S., \& Eilstein, D., Relations à court terme entre les niveaux de pollution atmosphérique et les admissions à l'hôpital dans huit villes françaises. Institut de veille sanitaire, 66 p., 2006.

[5] Havard, S., Deguen, S., Zmirou-Navier, D., Schillinger, C. \& Bard, D., Traffic-Related Air Pollution and Socioeconomic Status: A Spatial Autocorrelation Study to Assess Environmental Equity on a Small-Area Scale, Epidemiology, 20(2), pp. pp 223-230, 2009.

[6] Aschan-Leygonie, C. \& Baudet-Michel, S., Qualité de l'air et concentrations de dioxyde d'azote, in Données urbaines volume 5, ed. D., Pumain \& M.F. Mattei, Anthropos-Economica, Collection Villes: Paris pp. 335-348, 2007.

[7] Roorda-Knape, M.C., Janssen, N., De Hartog, J., Van Vliet, P., Harssema, H. \& Brunekreef, B., Air pollution from traffic in city districts near major motorways. Atmos Environ 1998;32:1921-1930

[8] Katsouyanni, K., Zmirou, D., Spix, C., Sunyer, J., Schouten, J.P., Pönkä, A., Anderson, H.R., Le Moullec, Y., Wojtyniak, B., Vigotti, M.A., \& Bacharova, L., Short-term effects of air pollution on health: a European approach using epidemiological time-series data. European Respiratory Journal, (8), pp. 1030-1038, 1995.

[9] ADEME, Classification et critères d'implantation des stations de surveillance de la qualité de l'air. Paris, Agence de l'Environnement et de la Maîtrise de l'Energie. 63p., 2002. 